\title{
Intravesical Electromotive Botulinum Toxin in Women with Overactive Bladder - A Pilot Study
}

\author{
Hjalmar A Schiotz, MD, PhD*, Ha T Mai, MD, Renata Zabielska, MD, PhD \\ Department of Obstetrics \& Gynecology, Vestfold Hospital Trust, Tonsberg, Norway
}

"Corresponding Author: Hjalmar A Schiotz, Department of Obstetrics \& Gynecology, Vestfold Hospital Trust, Tønsberg, Norway, Email: s-schi@online.no

\begin{abstract}
:
Introduction: Cystoscopic injection of botulinum toxin into the bladder wall is a well established, minimally invasive treatment option in patients with overactive bladder. This study was done to evaluate a different way of delivering the drug, namely by bladder instillation by catheter and using electromotive drug application (EMDA).

Methods: 14 women with treatment resistant $O A B$ underwent a single outpatient treatment session with botulinum toxin A (Botox®) 200 Allergan Units instilled into the bladder. A pulsed current electric generator delivered $20 \mathrm{~mA}$ for 30 minutes via a specially designed bladder catheter and two skin electrodes. Primary endpoint was number of leakage episodes per 24 hours.

Results: At both one and three months there was statistically significant reduction in leakage episodes and grams leakage per 24 hours as well as in UDI6 score. Statistically significant improvement was seen for IIQ7 and ICIQ-OAB SF scores and number of voids per 24 hours at one month, but not at three months. At one month 6/14 (43\%) were responders (Treatment Benefit VAS score $\geq 5$ ), falling to 5/14 (36\%) at 3 months and $3 / 14$ (21\%) at 6 months. There were three cases of uncomplicated cystitis (14\%), no change in postvoid residuals and no cases of urinary retention.
\end{abstract}

Conclusions: Electromotive botulinum toxin administration is a simple and safe non-invasive outpatient method with no need for anesthesia or cystoscopy. A statistically significant improvement in overactive bladder symptoms was found after a single treatment session. However, this was not a comparative study and further studies with this method are indicated.

Keywords: Botulinum toxin, EMDA, Overactive bladder, Treatment, Urinary incontinence, Women

Abbreviations: Electromotive Drug Application (EMDA), International Consultation on Incontinence Overactive Bladder Short Form (ICIQ-OAB SF), Incontinence Impact Questionnaire (IIQ-7), Overactive bladder (OAB), Urinary tract infection (UTI), Urogenital Distress Inventory (UDI-6), Visual Analog Scale $(V A S)$.

\section{INTRODUCTION}

Management of overactive bladder (OAB) can be difficult, and when primary treatment has failed to give sufficient improvement, cystoscopic injection of botulinum toxin into the bladder wall is now a well established treatment option $^{[1-4]}$. This is a minimally invasive outpatient or day case procedure. Among the currently available botulinum toxin preparations only onabotulinum toxin A (Botox ${ }^{\circledR}$ ) is licensed for treatment of $\mathrm{OAB}$. The recommended dose for non-neurogenic $\mathrm{OAB}$ is 100 Allergan units per treatment ${ }^{[5]}$. With this dose the response rate is above $60 \%$ in most studies (range 37-
$70 \%$, Table 3), typically with a 20-50\% reduction in incontinence episodes (i.e. 2-3 fewer leaks per 24 hours), $23-55 \%$ of patients achieving continence, and a statistically significant improvement in quality of life measures ${ }^{[2-4,6-8]}$. The main complications are a $5-36 \%$ risk of UTI ${ }^{[2-6,9]}$ and a $4-11 \%$ risk of impaired bladder emptying requiring catheterization ${ }^{[1,3,4,6,9]}$. Some patients also experience postoperative pain and dysuria. Systemic adverse effects are very rare with this dose. The effect of cystoscopic injection of botulinum toxin is temporary, with median duration of 
effect around six months. However, the treatment may be repeated, and responders typically receive a new injection after 6-8 months ${ }^{[5,9,10]}$.

EMDA (Electromotive Drug Application) is a method for enhancing absorption of drugs into tissues ${ }^{[11]}$. By creating an electric field drugs can be transported through a physiological barrier, thereby increasing the transfer of a drug into the target tissue. The active processes in EMDA are electrophoresis and iontophoresis.

EMDA has been used in the urinary bladder to increase the effect of local anesthesia ${ }^{[12]}$, in treatment with cytostatic drugs in superficial bladder cancer ${ }^{[13]}$ and in the treatment of $\mathrm{OAB}$ $[11,14]$. We used this method with botulinum toxin in our study.

Only two clinical studies on EMDA and OAB using botulinum toxin in $\mathrm{OAB}$ patients have so far been published, both with pediatric patients [15,16]. Kajbafzadeh and coworkers have published two case series with intravesical botulinum toxin A (Dysport ${ }^{\circledR}$ ) with EMDA in children with myelomeningocele, one focusing on urinary incontinence due to neurogenic detrusor overactivity ${ }^{[15]}$ and one focusing on children with both neuropathic bladder and bowel dysfunction ${ }^{[16]}$. Their results were good and the treatment was virtually without complications. Kajbafzadeh and coworkers have also shown in a rabbit study using immunohistochemical staining that botulinum toxin A (using Dysport ${ }^{\circledR}$ ) was distributed evenly and deeply into the bladder wall with EMDA, while the distribution was weak and patchy with cystoscopic injection ${ }^{[17]}$, supporting the utility of the EMDA method. We are not aware of any published studies on the use of botulinum toxin and EMDA in adults with OAB.

Our pilot study was done to evaluate the effect of botulinum toxin A with EMDA in women with severe, treatment refractory OAB.

\section{MATERIALS AND METHODS}

After written, informed consent 14 women with severe, treatment resistant $\mathrm{OAB}$ were recruited from the gynecological outpatient department. All had tried other treatments for OAB (bladder training, antimuscarinics, mirabegron, electrostimulation) with insufficient effect and were candidates for standard botulinum toxin treatment by cystoscopic injection of Botox. Inclusion criteria were $\mathrm{OAB}$ of more than 3 months duration, failed conservative and pharmacological treatment and indication for standard cystoscopic injection of botulinum toxin. Exclusion criteria were age $<18$ years, mixed incontinence with dominant stress incontinence, ongoing urinary tract infection and contraindication to treatment with botulinum toxin. The trial was designed to mirror our clinical practice and participants were not asked to stop other $\mathrm{OAB}$ treatment before inclusion. Follow-up time was 6 months.

The primary efficacy end-point was change in number of leakage episodes per 24 hours. Secondary endpoints were: change in grams leakage, number of voids and mean voided volume on a 24 hour voiding chart, change in score on the validated instruments UDI-6 (Urogenital Distress Inventory 6), IIQ-7 (Incontinence Impact Questionnaire 7), ICIQOAB SF (International Consultation on Incontinence Overactive Bladder Short Form, an instrument specifically for overactive bladder problems) and a treatment satisfaction VAS, and change in flow rate and postvoid residual urine. Adverse events such as UTI and need for catheterization were recorded.

In the literature treatment success is commonly defined as more than $50 \%$ improvement. We therefore classified participants with a treatment satisfaction VAS score $\geq 5$ as responders and those with a score $<5$ as non-responders. Nonresponders were allowed to leave the study after 3 months and were offered standard botulinum toxin a treatment by cystoscopic injection.

\subsection{Treatment Procedure}

The bladder was emptied and $60 \mathrm{~mL}$ of normal saline with 200 Allergan units of on a botulinum toxin A (Botox $\left.{ }^{\circledR}\right)$ were instilled into the bladder. A pulsed current electric generator (Physionizer Mini30N2, Physion Srl, Mirandola, Italy) delivered $20 \mathrm{~mA}$ via a specially designed urinary catheter with a spiral silver electrode (Physion Srl, Mirandola, Italy) and two suprapubic skin electrodes. The positive electrode was located in the bladder and the negative electrodes on the skin. Treatment time was 30 minutes. Antibiotic prophylaxis was given with a single dose of two tablets 
trimethoprim $80 \mathrm{mg} /$ sulfamethoxazole $400 \mathrm{mg}$ (Bactrim $\left.{ }^{\circledR}\right)$.

The participants were seen in the clinic after 2 weeks bringing a 24 hour voiding chart. At the visit urine flow rate and postvoid residual were measured, and scores on UDI-6, IIQ-7, ICIQ-SF and a treatment satisfaction VAS were recorded. After 4 weeks and 3 months the participants reported by letter with a 24 hour voiding chart, UDI-6, IIQ-7, ICIQ-OAB SF and a treatment satisfaction VAS, and after 6 months they were again seen in the clinic with the same procedure as the 2 week visit. All participants were free to contact the study team at any time.

The study was approved by the Regional Ethics Committee of South-East Norway.

Trial registration: Clinical Trials. gov: NCT02735499

\subsection{Statistics}

One-sided Wilcoxon signed-rank test and paired t-test were used with level of significance set at 0.05 .

\section{Results}

Demographics of the participants are given in Table 1 and the main results in Table 2. Most of

Table1. Demographics of participants $(N=14)$. the participants had transient, mild, painless erythema of the abdominal skin for a few hours after the treatment. Otherwise there were no adverse events except three episodes of acute cystitis (14\%) in two patients who both have a history of recurrent urinary tract infections. Two episodes occurred within a week of treatment and the third eight weeks later. No participants had impaired bladder emptying or a need for catheterization. Nine participants elected to leave the study after three months, leaving five who completed six months follow-up. As shown in Table 2 the response rate was $43 \%$ at one month, $36 \%$ at three months and $21 \%$ at six months with continence achieved in $43 \%, 21 \%$ and $7 \%$, respectively. At six months, all the three responders scored 8 on the treatment satisfaction VAS. Among the seven patients who used $\mathrm{OAB}$ medication at inclusion, four stopped within the first two weeks; two of them started again after three months and the other two after six months. Among five patients who subsequently received intravesical cystoscopic injection (100 units onabotulinum toxin A), two were classified as responders and three as nonresponders after a mean of three months followup

\begin{tabular}{|l|c|c|c|c|c|c|}
\hline & Age (years) & Weight (kg) & Height (cm) & BMI & Parity & $\begin{array}{c}\text { On OAB } \\
\text { medication }\end{array}$ \\
\hline Mean & 59.9 & 75.3 & 1.67 & 27.1 & 1.4 & 7 Yes \\
\hline SD & 13.90 & 17.56 & 0.09 & 6.02 & 1.02 & 7 No \\
\hline Range & $31-79$ & $58-110$ & $1.50-1.75$ & $16-38$ & $0-3$ & \\
\hline
\end{tabular}

Table2. Main Results

\begin{tabular}{|c|c|c|c|c|c|c|c|}
\hline & $\mathbf{0}$ & 1 month & & 3 months & & 6 months & \\
\hline & $\mathrm{N}=14$ & $\mathrm{~N}=14$ & & $\mathrm{~N}=14$ & & $\mathrm{~N}=5$ & \\
\hline & Mean (SD) & Mean (SD) & $\mathbf{p}_{1}$ & Mean (SD) & $\mathbf{p}_{\mathbf{2}}$ & Mean (SD) & $\mathbf{p}_{3}$ \\
\hline Leakage episodes/24 hours (N) & $5.5(3.8)$ & $2.2(2.6)$ & 0.001 & $3.3(3.2)$ & 0.01 & $2.4(0.9)$ & 0.01 \\
\hline Leakage / 24 hours (grams) & $105(140)$ & $43(76.7)$ & 0.004 & $56(85.6)$ & 0.025 & $11(8.9)$ & 0.15 \\
\hline Voids / 24 hours $(\mathrm{N})$ & $11(2.2)$ & $9.2(3.1)$ & 0.023 & $11.1(3.3)$ & 0.44 & $9.4(0.9)$ & 0.37 \\
\hline Mean volume / void (mL) & $172(44.4)$ & $186(65.7)$ & 0.22 & $175(64.1)$ & 0.45 & $227(63.0)$ & 0.06 \\
\hline Qmax (mL/sek) & $22.7(17.1)$ & & & & & $25.3(14.6)$ & 0.09 \\
\hline Post void residual (mL) & $33(33.2)$ & & & & & $31(27.8)$ & 0.09 \\
\hline UDI6 score & $9.1(3.0)$ & $6.3(3.0)$ & 0.002 & $7.4(3.4)$ & 0.045 & $6.8(2.5)$ & 0.05 \\
\hline IIQ7 score & $11.3(5.9)$ & $7.0(6.2)$ & 0.001 & $9.3(6.3)$ & 0.05 & $3.6(2.0)$ & 0.04 \\
\hline ICIQ-OAB SF score & $9.3(2.5)$ & $7.9(2.9)$ & 0.027 & $8.9(2.7)$ & 0.11 & $7.2(2.2)$ & 0.11 \\
\hline Continent (N) (\%) & 0 & $6(42.9 \%)$ & & $3(21.4 \%)$ & & $1(7.1 \%)$ & \\
\hline Treatment satisfaction $(0-10)$ & & $4.9(3.5)$ & & $3.3(3.8)$ & 0.26 & $5(4.1)$ & \\
\hline Responders (N) (\%) & & $6(43 \%)$ & & $5(36 \%)$ & & $3(21 \%)$ & \\
\hline
\end{tabular}

Note: Statistics by one-sided Wilcoxon signed-rank test $\left(p_{1}\right.$ and $\left.p_{2}\right)$ and paired test $\left(p_{3}\right)$.

\section{DISCUSSION}

This was a pilot study to gain initial experience with bladder instillation of botulinum toxin A and EMDA in adults as this has never been reported in the literature. There are two published studies on this method in children ${ }^{[15,16]}$, but none in adults. The response rate in our study, defined as Treatment Benefit VAS score $\geq 5$, was $43 \%$ at one month, $36 \%$ at 3 months and $21 \%$ at 6 months. At both one and 
three months there was a statistically significant reduction in the number of leakage episodes (the primary endpoint) and grams leakage per 24 hours as well as in the UDI 6 score, while number of voids per 24 hours and IIQ7 and ICIQ SF scores showed statistically significant reduction at one month only. It appears therefore that the method works reasonably well and there were few complications in our study.

\subsection{Comparison with Cystoscopic Injection}

At present, among the currently available botulinum toxin preparations only on a botulinum toxin A (Botox $\left.{ }^{\circledR}\right)$ is licensed for treatment of $\mathrm{OAB}$. The recommended dose for non-neurogenic $\mathrm{OAB}$ is 100 Allergan units per treatment ${ }^{[5]}$. With this dose the response rate (in the reports usually defined as $>50 \%$ improvement or 'improved' or 'greatly improved' on
Treatment Benefit Scales) is in excess of $60 \%$ in most studies (range $37-70 \%$ ), typically with a $20-50 \%$ reduction in incontinence episodes (i.e. about 3 fewer leaks per 24 hours), 23-55\% of patients achieving continence, and statistically significant improvement in quality of life measures ${ }^{[2-4,6-8]}$ (Table 3). The response rate in our study is somewhat lower at $43 \%$ at one month and $36 \%$ at three months, and while there was statistically significant reduction in incontinence episodes $(\mathrm{p}=0.01)$ and leakage $(\mathrm{p}=0.025)$, the numbers are lower than those reported after cystoscopic injection. However, it is interesting to note that three of the five nonresponders who subsequently received cystoscopic injection of Botox were still nonresponders

Table3. Studies using Botox $100 \mathrm{U}$ in female patients $U$, Allergan units

\begin{tabular}{|c|c|c|c|c|c|c|c|c|}
\hline Author [Reference] & $\begin{array}{c}\text { Total } \\
(\mathbf{N})\end{array}$ & $\begin{array}{l}100 U \\
(N)\end{array}$ & $\begin{array}{c}\text { Follow } \\
\text { up }\end{array}$ & $\begin{array}{l}\text { Response } \\
\text { rate }(\%)\end{array}$ & $\begin{array}{c}\text { Leaks/24h } \\
(\mathrm{N})\end{array}$ & $\begin{array}{c}\text { Continent } \\
(\%)\end{array}$ & $\begin{array}{l}\text { Retention/ } \\
\text { CIC }(\%)\end{array}$ & $\begin{array}{l}\text { UTI } \\
(\%)\end{array}$ \\
\hline $\begin{array}{l}\text { Dmochowski } 2010 \\
\text { [6] } \\
\text { 50-100-150-200- } \\
\text { 300U vs. placebo }\end{array}$ & 313 & 48 & $\begin{array}{c}12 \\
\text { weeks }\end{array}$ & 37 & -2.6 & & 10.9 & 36 \\
\hline $\begin{array}{l}\text { Denys 2012 [2] } \\
50-100-150 U \text { vs. } \\
\text { placebo }\end{array}$ & 77 & 22 & $\begin{array}{c}6 \\
\text { months }\end{array}$ & 65 & -3 & 55 & 4.5 & 4.6 \\
\hline $\begin{array}{l}\text { Fowler 2012 [8] } \\
50-100-150-200- \\
\text { 300U vs. placebo }\end{array}$ & 288 & 55 & $\begin{array}{c}36 \\
\text { weeks }\end{array}$ & 68 & -3 & 29.8 & & \\
\hline $\begin{array}{l}\text { Visco } 2012 \text { [7] } \\
\text { 100U vs. solifenacin }\end{array}$ & 241 & 113 & $\begin{array}{c}6 \\
\text { months }\end{array}$ & 70 & -3.3 & 27 & 5.5 & 33 \\
\hline $\begin{array}{l}\text { Chapple 2013 [3] } \\
\text { 100U vs. placebo }\end{array}$ & 541 & 277 & $\begin{array}{c}12 \\
\text { weeks }\end{array}$ & 62.8 & -3 & & 6.9 & 20.4 \\
\hline $\begin{array}{l}\text { Nitti } 2013 \text { [4] } \\
\text { 100U vs.placebo }\end{array}$ & 550 & 278 & $\begin{array}{c}12 \\
\text { weeks }\end{array}$ & 60.8 & -2.65 & 22.9 & 5.4 & 15.5 \\
\hline
\end{tabular}

\subsection{Duration of Effect}

With cystoscopic injection of botulinum toxin the duration of benefit is usually about six months ${ }^{[5,9,10]}$. While the initial response rate was lower in our study, $21 \%$ of the patients were still classified as responders at six months, showing that the benefit is long lasting in some of the patients.

\subsection{Complications}

There were few treatment related complications in our study, only three cases of acute cystitis in two patients who both have a history of recurrent UTI's. Two cases occurred early and were treatment related while the last occurred after eight weeks and thus probably not treatment related. Otherwise no complications were seen and there were no cases of impaired bladder emptying. It is possible that a more aggressive antibiotic prophylaxis might have reduced the number of UTI's.

\subsection{Instillation Treatments}

Instillation treatment can be used for several bladder conditions. Instillation treatment with different compounds for painful bladder syndrome/interstitial cystitis is well established ${ }^{[19]}$. For superficial bladder cancer cytotoxic drugs with EMDA is used ${ }^{[13]}$. For OAB a number of compounds have been tried, but none appear to have come into very widespread use.

Only a few studies using intravesical EMDA in OAB patients have been published. Di Stasi et al. reported significant improvement in several urodynamic parameters with EMDA using oxybutinin in a pilot study in $2001^{[20]}$. GauruderBurmester et al. in 2008 and Bach et al. in 2009 used EMDA with a mixture of lidocaine, 
epinephrine and dexamethasone with a triple cycle treatment. Their results were unconvincing and good, respectively ${ }^{[14,21]}$. Petrou et al. used a mixture of Botox and DMSO in 2009 with unconvincing results ${ }^{[22]}$. No further studies have been published by these groups.

Some instillation methods employ a carrier substance to improve treatment effect by prolonging contact with the bladder mucosa ${ }^{[18]}$. Lately, liposomes acting as drug carriers have come under study for OAB ${ }^{[23]}$. With this method, different molecules are added to liposomes. The compound then attaches to the bladder mucosa for a prolonged period of time, facilitating transfer of the drug into the bladder wall. A few small studies using botulinum toxin A with liposomes have been published [24, 25]. The results so far indicate that this is an interesting method, but comparative studies have not been published, and it does not appear to be superior to EMDA or other instillation methods.

\subsection{Improving Our Results}

Increasing the dose of Botox might improve the response rate, but would also increase the cost, and might increase the risk of impaired bladder emptying. Increasing treatment time would probably not be of any use, as most of the drug transfer takes place within the first 15 minutes (personal communication Paolo Mironi, Physion Srl, Italy). We used $20 \mathrm{~mA}$ power in our study. Increasing the power might not be advisable as a number of our patients experienced transient skin erythema at this setting. While substantially similar after reconstitution ${ }^{[26]}$ the different botulinum toxin a preparations on the market are slightly different from each other due to different production methods, and a different preparation might possibly have a better effect. In their studies on EMDA and botulinum toxin A in children, Kajbafzadeh and coworkers used Dysport ${ }^{\circledR}$ with good results ${ }^{[15,16]}$. We used Botox ${ }^{\circledR}$ in our study because this is the only botulinum toxin preparation currently licensed for OAB. A comparative study is required to address this point.

\subsection{Limitations of the Study}

The main limitations of this study are its small number of subjects as well as being noncomparative. Also, it could be argued that not stopping $\mathrm{OAB}$ medication has polluted the results. However, we feel that it fulfills its role as a pilot study and shows that the method is safe and feasible and has promising results.

\section{CONCLUSION}

This pilot study shows that electromotive botulinum toxin administration is a feasible, simple and safe non-invasive outpatient method with no need for anesthesia or cystoscopy. It can be administered by a nurse. A statistically significant improvement in overactive bladder problems was found after a single treatment session. Treatment response was $43 \%$ at one month, $36 \%$ at three months and $21 \%$ at six months. There were no complications apart from three cases of acute cystitis of which one may be classified as not treatment related.

However, this was not a comparative study, and further studies of adequate power are required. This method has the potential of becoming an alternative to cystoscopic injection of botulinum toxin.

\section{FUNDING}

The study was supported by grants from SouthEastern Norway Regional Health Authority (grant number 15/00779-8) and Vestfold Hospital Trust.

\section{ACKNOWLEDGEMENT}

The Physionizer apparatus was lent us free of charge by Jump Start Consulting Limited, Bedfordshire, UK.

\section{REFERENCES}

[1] Duthie JB, Vincent M, Herbison GP, Wilson DI, Wilson D. Botulinum toxin injections for adults with overactive bladder syndrome. Cochrane Database of Systematic Reviews 2011, Issue 12. Art. No.: CD005493. http:// onlinelibrary.wiley.com/doi/10.1002/14651858. CD005493.pub3/abstract.

[2] Denys P, Le Normand L, Ghout I, Costa P, Chartier-Kastler E, Grise P, Hermieu JF, Amarenco G, Karsenty G, Saussine C, BarbotF, for the Vesitox study group in France. Efficacy and safety of low doses of on abotulinum toxin A for the treatment of refractory idiopathic overactive bladder: a multicentre, double-blind, randomised, placebo-controlled dose-ranging study. Eur Urol 2012; 61:520-529.

[3] Chapple C, Sievert K-D, MacDiarmid S, Khullar V, Radziszewski P, Nardo C, Thompson C, Zhou J, Haag-Molken teller C. On abotulinum toxinA 100U significantly improves all idiopathic overactive bladder symptoms and quality of life in patients with overactive bladder and urinary 
incontinence: a randomised, double-blind, placebocontrolled trial. Eur Urol 2013; 64:249-256.

[4] Nitti VW, Dmochowski R, Herschorn S, Sand P, Thompson C, Nardo C, Yan X, HaagMolkenteller C; EMBARK Study Group. On a botulinum toxin A for the treatment of patients with overactive bladder and urinary incontinence: results ofa phase 3, randomized, placebo controlled trial. J Urol 2013; 189:2186-93.

[5] Tincello D, Fowler CJ, Slack M. Botulinum Toxin for an Overactive Bladder. Royal College of Obstetricians and Gynaecologists. Scientific Impact Paper No. 42. February2014. https://www.rcog.org.uk/globalassets/document s/guidelines/sip_42_13022014.pdf.

[6] Dmochowski R, Chapple C, Nitti CW, Chancellor M, Everaert K, Thompson C. Efficacy and safety of on a botulinum toxin A for idiopathic overactive bladder: a doubleblind, placebo controlled, randomized, dose ranging trial. J Urol 2010; 184: 2416-22.

[7] Visco AG, Brubaker L, Richter HE, Nygaard I, Paraiso MF, Menefee SA, Schaffer J, Lowder J, Khandwala S, Sirls L, Spino C, Nolen TL, Wallace D, Meikle SF; Pelvic Floor Disorders Network. Anti cholinergic therapy vs. on a-botulinum toxinA for urgency urinary incontinence. N Engl J Med 2012; 367:1803-1813.

[8] Fowler CJ, Auerbach S, Ginsberg D, Hale D, Radziszewski P, Rechberger T, Patel VD, Zhou J, Thompson C, Kowalski JW. On a botulinum toxin A improves health-related quality of life in patients with urinary incontinence due to idiopathic overactive bladder: a 36-week, double-blind, placebo-controlled, randomized, dose-ranging trial. Eur Urol 2012; 62: 148-157.

[9] Nitti VW, Ginsberg D, Sievert KD, Sussman D, Radomski S, Sand P, De Ridder D, Jenkins B, Magyar A, Chapple C. Durable efficacy and safety of long-term On a botulinum toxin A treatment in patients with overactive bladder syndrome: final results of a 3.5-year study. J Urol 2016; 196:791-800.

[10] Chibelean C, Nechifor-Boila IA. Botulinum neurotoxin A for overactive bladder treatment: advantages and pitfalls. Can J Urol 2015; 22:7681-89.

[11] CADTH. The Use of the Electromotive Drug Administration System in Patients with Overactive Bladder: A Review of the Clinical Effectiveness, Safety, and Cost-Effectiveness [Internet]. Ottawa (ON): Canadian Agency for Drugs and Technologies in Health; 2014 Sep 24. http:// www.ncbi.nlm.nih.gov/pubmed/ 25392902.

[12] Shurch B, Reitz A, Tenti G. Electromotive drug administration of lidocaine to anesthetize the bladder before botulinum-A toxin injections into the detrusor. Spinal Cord 2004; 42: 338341.
[13] National Institute for Health and Clinical Excellence. Interventional procedure overview of electrically-stimulated intravesical chemotherapy for superficial bladder cancer. IP 697 , 2008.https://www.nice.org.uk/guidance/ipg277/ documents/electricallystimulated-intra- vesicalchemotherapy-for-superficial-bladder-cancer interventional-procedures-overview2.

[14] Bach P, Worml and RT, Möhring C, Goepel M. Electromotive Drug-Administration: a pilot study for minimal-invasive treatment of therapy-resistant idiopathic detrusor over-activity. Neurourol Urodyn 2009; 28:209-213.

[15] Kajbafzadeh AM, Ahmadi H, MontaserKouhsari L, Sharifi-Rad L, Nejat F, BazarganHejazi S. Intravesical electromotive botulinum toxin type A administration - part II: Clinical application. Urology 2011; 77:439-45.

[16] Kajbafzadeh A-H, Sharifi-Rad L, Ladi-Seyedian SS. Intravesical electromotive botulinum toxin type A administration for management of concomitant neuropathic bowel and bladder dysfunction in children. Int J Colorectal Dis 2016; 31:1397-9.

[17] Kajbafzadeh AM, Montaser-Kouhsari L, Ahmadi $\mathrm{H}$, Sotoudeh M. Intravesical electromotive botulinum toxin type A administration: part I-Experimental study. Urology 2011; 77:1460-4.

[18] Hsu C-C, Chuang Y-C, Chancellor MB. Intravesical drug delivery for dysfunctional bladder. Int J Urol 2013; 20, 552-562.

[19] Dawson TE, Jamison J. Intravesical treatments for painful bladder syndrome/interstitial cystitis. Cochrane Database of Systematic Reviews 2007, Issue 4. Art. No.:CD006113. doi: 10.1002/ 14651858.CD006113.pub2.

[20] Di Stasi SM, Giannantoni A, Vespasiani G, Navarra P, Capelli G, Massoud R, Stephen RL. Intravesical electromotive administration of oxybutynin in patients with detrusor hyper-reflexia unresponsive to standard anti-cholinergic regimens. J Urol 2001; 165:491-8.

[21] Gauruder-Burmester A, Biskupskie A, Rosahl A, Tunn R. Electromotive drug administration for treatment of therapy-refractory overactive bladder. Int Braz J Urol 2008; 34:758-64.

[22] Petrou SP, Parker AS, Crook JE, Rogers A, MetzKudashick D, Thiel DD. Botulinum A Toxin/ Dimethyl Sulfoxide Bladder Instillations for Women With Refractory Idiopathic Detrusor Over activity: a phase 1/2 study. Mayo Clin Proc 2009; 84:702-6.

[23] Janicki JJ, Chancellor MB, Kaufman J, Gruber MA, Chancellor DD. Potential Effect of Liposomes and Liposome-Encapsulated Botulinum Toxin and Tacrolimus in the Treatment of Bladder Dysfunction. Toxins (Basel) 2016; 8: (3). pii: E81. doi: $10.3390 /$ toxins 8030081 .

[24] Chuang YC, Kaufmann JH, Chancellor DD, Chancellor MB, Kuo HC. Bladder instillation 
of liposome encapsulated on abotulinum toxin A improves overactive bladder symptoms: a prospective, multicenter, double-blind, randomized trial. J Urol 2014; 192:1743-9.

[25] Kuo HC, Liu HT, Chuang YC, Birder LA, Chancellor MB. Pilot study of liposome- encapsulated On abotulinum toxin A for patients with overactive bladder: a single-center study. Eur Urol 2014; 65:1117-24.

[26] Frevert J. Pharmacological, biological, and clinical properties of botulinum neurotoxin type A products. Drugs RD 2015; 15:1-9.

Citation: Hjalmar A Schiotz, Ha T Mai, Renata Zabielska. Intravesical Electromotive Botulinum Toxin in Women with Overactive Bladder - A Pilot Study. ARC Journal of Gynecology and Obstetrics. 2017; 2(2):4-10. doi:dx.doi.org/10.20431/2456-0561.0202002.

Copyright: (C) 2017 Authors. This is an open-access article distributed under the terms of the Creative Commons Attribution License, which permits unrestricted use, distribution, and reproduction in any medium, provided the original author and source are credited. 